\title{
Treatment of Crohn's anal fistulas guided by magnetic resonance imaging
}

\author{
Jacek Hermann ${ }^{1}$, Piotr Stajgis ${ }^{2}$, Barbara Kołodziejczak³ ${ }^{3}$ Piotr Eder ${ }^{4}$, Tomasz Banasiewicz ${ }^{1}$ \\ ${ }^{1}$ Department of General and Endocrinological Surgery, and Gastroenterological Oncology, Poznan University \\ of Medical Sciences, Poznan, Poland \\ ${ }^{2}$ Department of Radiology, Poznan University of Medical Sciences, Poznan, Poland \\ ${ }^{3}$ Department of Computer Science and Statistics, Poznan University of Medical Sciences, Poznan, Poland \\ ${ }^{4}$ Department of Gastroenterology, Human Nutrition, and Internal Medicine, Poznan University of Medical Sciences, Poznan, \\ Poland
}

Gastroenterology Rev 2019; 14 (1): 55-61

DOI: https://doi.org/10.5114/pg.2019.83426

Key words: anal fistula, Crohn's disease, magnetic resonance imaging.

Address for correspondence: Jacek Hermann MD, PhD, Department of General and Endocrinological Surgery, and Gastroenterological Oncology, Poznan University of Medical Sciences, 49 Przybyszewskiego St, 60-355 Poznan, Poland, phone: +48 600257458 , e-mail: jacekhermann@gmail.com

\begin{abstract}
Introduction: Clinical evaluation of the Crohn's anal fistulas (CF) closure is inadequate to some extent due to earlier closure of cutaneous openings compared to fistulous tracts. There is a need for a more accurate method of assessment.

Aim: To compare clinical signs of CF with radiological findings, before and after treatment, to follow complete closure.

Material and methods: It was a retrospective study of 23 patients suffering from CF admitted to a single specialist centre, who were treated with a combination of surgical and biological therapy. Fistula healing was evaluated with fistula drainage assessment classification (FDA), perianal disease activity index (PDAI), and van Assche magnetic resonance imaging score (MRI) before and 3 months after surgery and induction of the biological treatment.

Results: Clinical response occurred in $13(57 \%)$ patients 3 months after induction treatment. Complete clinical response was achieved in $8(35 \%)$ patients, whereas partial response occurred in $5(22 \%)$ patients. Persistence of a fistula tract was visualised on MRI in $4(50 \%)$ patients with clinical closure.

Conclusions: The healing process of CF should be monitored by MRI due to the discrepancy between premature closure of external openings and fistulous tracts. Prolonged biological therapy until complete healing of anal fistulas confirmed on MRI might improve the results of treatment.
\end{abstract}

\section{Introduction}

There is still a high rate of failure and recurrence after treatment of anal fistulas in the course of Crohn's disease (CD). A combination of surgical and medical methods appears today the most effective therapy [1]. However, results of treatment are still unsatisfactory because the rate of healing after that combined treatment ranges from $30 \%$ to $70 \%$ [2]. Perhaps, inadequate assessment of the healing process of fistulas is a cause of poor effects of treatment, among others. At present, closure of fistulas is recognised, on a clinical basis, as a cessation of discharge from the external opening in most patients. Actually, that absence of discharge may not reflect what is happening to the fistula canal, because the tract may remain open in some patients when the external orifice is already closed. Premature withdrawal of biological therapies in patients with unhealed fistulous tracts may be responsible for the relatively high risk of recurrences [2]. Magnetic resonance imaging (MRI) is a cross-sectional technique, which due to its lack of an ionising radiation and accurate characterisation of anal fistulas in CD with their relationship to the anal sphincter and levator ani muscles, emerges as a radiological method of choice. The MRI shows excellent sensitivity and specificity, respectively $100 \%$ and $86 \%$, in the detection of fistulas, and respectively $96 \%$ and $97 \%$ in the detection of abscesses. The radiological signs of healing may indicate patients in whom fistulas 
were completely closed, and the biological treatment could be safely withdrawn [3].

\begin{abstract}
Aim
The aim of this study was to compare clinical signs of Crohn's anal fistulas (CF) with radiological findings, obtained from MRI, before and after combination of the surgical and biological treatment, to confirm the healing process, and as a result to determine the optimal time of biological therapy withdrawal, on the basis of our own material and literature.
\end{abstract}

\section{Material and methods}

Medical records of 23 patients who were treated for CF between 2014 and 2016 in a single specialist centre were retrospectively evaluated. That group consisted of $10(43 \%)$ males and 13 females, with mean age 39 years (range: $29-60$ years). Median duration of CD before the present treatment was 6 years (range: 1-15 years). Ileocolonic disease was present in 14 (61\%) patients, colonic lesions occurred in 8 (35\%) patients, and the perianal region was affected exclusively in 1 (4\%) patient. Crohn's disease was diagnosed on clinical basis, endoscopic measures, MRI, and histological findings. Patients after admission to hospital were examined under anaesthesia (EUA), during which a fistula was assessed and classified traditionally according to Parks because this method can influence the surgical management, as compared to other classifications [4]. Methods of examination such as EUA and MRI revealed transsphincteric fistulas also in 15 (65\%) patients, intersphincteric fistulas in 7 (30\%) patients, and a suprasphincteric fistula in 1 patient. Patients with bowel obstruction, septic complications within a region other than perianal, or with major co-morbidities were excluded from this study. Women who were pregnant or breastfeeding were also excluded. The surgical treatment consisted of incision and drainage of abscesses accompanying fistulas, curettage, cauterisation of fistulous tracts to remove the epithelium and septic granulation tissue with following irrigation of those canals to evacuate residual effusion and pus, and finally prolonged non-cutting seton placement. Next, the patients began routine biological treatment with infliximab (IFX). It was injected intravenously, 5-10 $\mathrm{mg} / \mathrm{kg}$ body weight in three doses at 0-2-6 weeks as an induction therapy and then every 8 weeks as a maintenance therapy. Fistula healing was evaluated with fistula drainage assessment classification (FDA) before and 3 months after induction of the biological treatment. Complete clinical response in the form of fistula closure was defined as the absence of discharge after gentle finger compression of an external opening and perianal tissues. Partial clinical response was defined as either closure of at least $50 \%$ of the fistulas or a significant decrease of discharge, and of perianal skin induration [5]. In addition, response to treatment was assessed with the perianal disease activity index (PDAI), to monitor the severity of anal fistulous disease through quantitative evaluation of several variables such as discharge, pain, type of fistulas, and perianal induration [6]. The MRI examination was performed on two 1.5T MRI (Magnetom Avanto, Siemens, Germany) with an eight-channel phased-array surface coil, in the supine position. Imaging was performed on sagittal, transverse, and coronal planes with transverse and coronal sequences oriented parallel and perpendicular to the anal canal, respectively. All examinations were performed with the same protocol, using the following sequences: T-2-weighted turbo spin echo (TSE) in sagittal, coronal, and transverse planes and fat-suppressed T-2-weighted TSE in transverse and coronal planes. All MRI images were evaluated by an experienced radiologist [7]. The MRI scans were assessed according to van Assche activity score (MRI) before and 3 months after IFX injection, which allowed quantitative assessment of parameters reflecting fistulous anatomy, such as number of tracts, type and extension, and degree of inflammation within a fistula through evaluation of hyperintensity, collections, and rectal wall involvement [8]. A total of 23 patients were divided into two groups: group I consisted of 13 patients who responded to the treatment, and group II comprised 10 patients who did not respond to therapy (Table I).

\section{Statistical analysis}

Analysed data are presented as medians with range or interquartile range. Categorical data are presented as percentages. Differences in overall PDAI and MRIs among two groups (responders and non-responders) were detected by Mann-Whitney U-tests. The Wilcoxon signed-rank test for comparing PDAI with MRIs before and after treatment were used. Fischer's exact test was used to examine the significance of the association between the two kinds of classification. The stepwise regression with forward selection was used to estimate the impact of independent factors on the level of PDAI after treatment. Variables were chosen based on their overall effects within the model. Analyses were performed using the statistical package Statistica v. 12.0 (StatSoft. Inc., Tulsa, OK, USA). All tests were considered significant at $p<0.05$.

\section{Results}

Clinical response occurred in 13 (57\%) patients 3 months after induction of treatment. Complete clinical response, i.e. closure of all fistulas, was achieved in 8 (35\%) patients, whereas partial response occurred 
Table I. Characteristics of patients according to the results of treatment

\begin{tabular}{|c|c|c|c|c|c|c|}
\hline Parameter & & $\begin{array}{l}\text { Group I }(n=13) \\
\text { Responders }\end{array}$ & Percent & $\begin{array}{c}\text { Group II }(n=10) \\
\text { Nonresponders }\end{array}$ & Percent & Significance \\
\hline \multirow[t]{2}{*}{ Gender } & Male & 5 & 38 & 5 & 50 & 0.685 \\
\hline & Female & 8 & 62 & 5 & 50 & \\
\hline Age, mean [years] & & $36 \pm 7.6$ & & $42 \pm 8.8$ & & 0.093 \\
\hline \multirow[t]{3}{*}{ Type of disease } & Colonic & 5 & 38.5 & 3 & 30.0 & 0.816 \\
\hline & Ileocolonic & 7 & 53.8 & 7 & 70.0 & \\
\hline & Perianal & 1 & 7.7 & 0 & 0 & \\
\hline \multirow[t]{2}{*}{ Previous surgery } & Resection & 6 & 46.2 & 5 & 50.0 & 1 \\
\hline & Perianal procedures & 7 & 53.8 & 5 & 50.0 & \\
\hline \multirow{2}{*}{$\begin{array}{l}\text { Fistulas } \\
\text { complexity }\end{array}$} & Simple & 8 & 61.5 & 4 & 40.0 & 0.414 \\
\hline & Branched & 5 & 38.5 & 6 & 60.0 & \\
\hline \multirow[t]{3}{*}{ No of tracts } & 1 & 11 & 84.6 & 6 & 60.0 & 0.499 \\
\hline & 2 & 1 & 7.7 & 1 & 10.0 & \\
\hline & 3 & 1 & 7.7 & 3 & 30.0 & \\
\hline \multirow{3}{*}{$\begin{array}{l}\text { Relation to } \\
\text { sphincters }\end{array}$} & Intersphincteric & 7 & 53.8 & 0 & 0 & 0.003 \\
\hline & Transsphincteric & 5 & 38.5 & 10 & 100 & \\
\hline & Suprasphincteric & 1 & 7.7 & 0 & 0 & \\
\hline \multirow[t]{2}{*}{ Extension } & Infralevatoric & 11 & 84.6 & 7 & 70.0 & 0.618 \\
\hline & Supralevatoric & 2 & 15.4 & 3 & 30.0 & \\
\hline
\end{tabular}

in 5 (22\%) patients. On the other hand, persistence of a fistula tract was visualized on MRI in 4 (50\%) patients with clinical closure, whereas the radiological sign of inflammation, i.e. hyperintensity in the fistulous tract, though improved, was still present in 2 patients with clinically healed fistulas and in one patient with partial response. Rectal wall thickening was absent in all the patients 3 months after induction therapy (Table II).

There were significant improvements in the group of patients who responded to treatment $(n=13)$ compared to others $(n=10)$ regarding PDAl classification $(p<0.001)$ and MRIs $(p=0.006)$, because the overall PDAl dropped in responders from 11 before treatment to 0 after, whereas in non-responders that score decreased from 11.5 to 7 (Figure 1 A, Table III). Similarly, the overall MRIs decreased from 8 to 4 in responders, and from 12.5 to 9.5 in non-responders (Figure $1 \mathrm{~B}$ ), Table III). As far as changes of MRI components between the patients who responded to treatment and the others are considered, the median decrease in the value of the anatomical criteria, such as the number of tracts $(p=0.008)$ and relation to sphincters $(p=0.035)$, was significantly less than the change in hyperintensity $(p=$ 0.005) in the fistula tract (Table IV).
Table II. MRI versus clinical response

\begin{tabular}{|c|c|c|c|}
\hline $\begin{array}{l}\text { Patient } \\
(n=13)\end{array}$ & $\begin{array}{l}\text { Clinical } \\
\text { response }\end{array}$ & Hyperintensity & Rectal wall \\
\hline 1 & Closure & Mild & Normal \\
\hline 2 & Closure & Absent & Normal \\
\hline 3 & Closure & Absent & Normal \\
\hline 4 & Closure & Absent & Normal \\
\hline 5 & Closure & Absent & Normal \\
\hline 6 & Closure & Mild & Normal \\
\hline 9 & $\begin{array}{c}\text { Decrease } \\
\text { of discharge }\end{array}$ & Mild & Normal \\
\hline 14 & $\begin{array}{c}\text { Decrease } \\
\text { of discharge }\end{array}$ & Absent & Normal \\
\hline 15 & $\begin{array}{c}\text { Decrease } \\
\text { of discharge }\end{array}$ & Absent & Normal \\
\hline 18 & $\begin{array}{c}\text { Decrease } \\
\text { of discharge }\end{array}$ & Absent & Normal \\
\hline 19 & Closure & Absent & Normal \\
\hline 20 & $\begin{array}{c}\text { Decrease } \\
\text { of discharge }\end{array}$ & Absent & Normal \\
\hline 22 & Closure & Absent & Normal \\
\hline
\end{tabular}


A

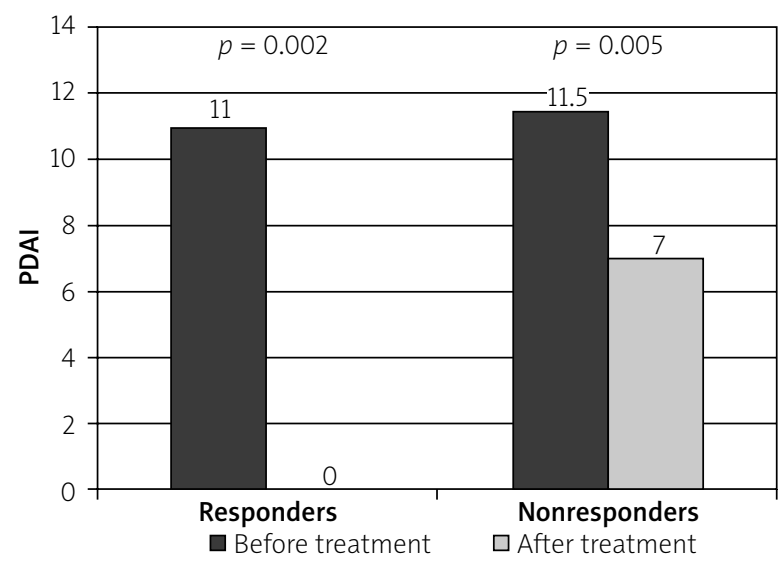

B

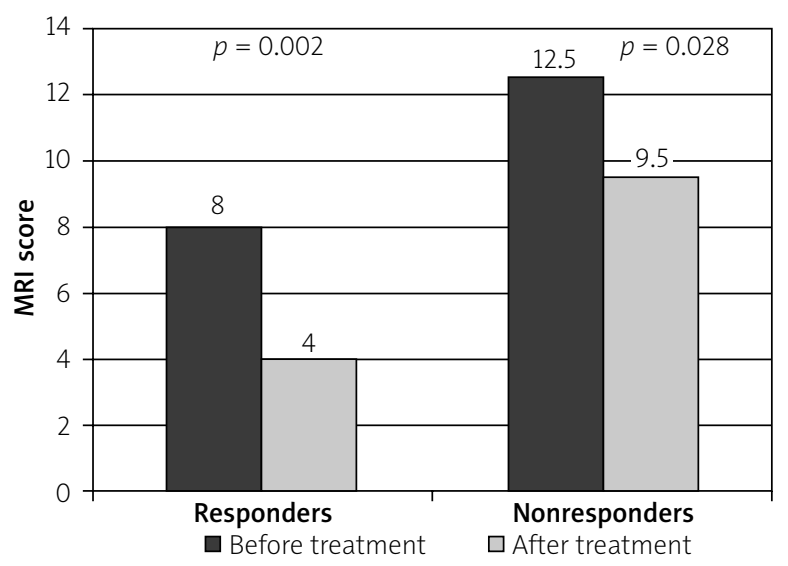

Figure 1. Changes in (A) perianal Crohn's disease activity index (PDAI) and (B) MRI-based score before and after treatment in clinically responding (A) and nonresponding (B) patients. Values shown on the graph represent medians

Table III. Changes in PDAI and MRIs before and after treatment in clinically responding (group I) and nonresponding (group II) patients

\begin{tabular}{|c|c|c|c|c|c|c|c|}
\hline \multirow[t]{2}{*}{ Parameter } & \multicolumn{3}{|c|}{ Group I ( $n=13)$ Responders } & \multicolumn{3}{|c|}{ Group II $(n=10)$ Nonresponders } & \multirow[t]{2}{*}{ Significance } \\
\hline & Median & Range & IQ range & Median & Range & IQ range & \\
\hline $\begin{array}{l}\text { PDAl before } \\
\text { treatment }\end{array}$ & 11 & $5-14$ & $7-12$ & 11.5 & $8-14$ & $9-13$ & 0.261 \\
\hline $\begin{array}{l}\text { PDAl after } \\
\text { treatment }\end{array}$ & 0 & $0-8$ & $0-5$ & 7 & $5-11$ & $5-8$ & 0.001 \\
\hline $\begin{array}{l}\text { MRI before } \\
\text { treatment }\end{array}$ & 8 & $7-18$ & $7-14$ & 12.5 & $7-16$ & 9-14 & 0.551 \\
\hline $\begin{array}{l}\text { MRI after } \\
\text { treatment }\end{array}$ & 4 & 0-12 & $0-4$ & 9.5 & $3-14$ & $7-10$ & 0.004 \\
\hline
\end{tabular}

Table IV. Changes of individual components in the MRI score

\begin{tabular}{|c|c|c|c|c|}
\hline Parameter & Total $(n=23)$ & $\begin{array}{l}\text { Group I }(n=13) \\
\text { Responders }\end{array}$ & $\begin{array}{c}\text { Group II }(n=10) \\
\text { Nonresponders }\end{array}$ & Significance \\
\hline \multirow[t]{2}{*}{ Number of tracts } & $0(-3-0)$ & $-1(-3-0)$ & 0 & 0.008 \\
\hline & $7 / 23$ & $7 / 13$ & $0 / 10$ & \\
\hline \multirow[t]{2}{*}{ Relation to sphincters } & $0(-2-0)$ & $0(-2-0)$ & 0 & 0.035 \\
\hline & $5 / 23$ & $5 / 13$ & $0 / 10$ & \\
\hline \multirow[t]{2}{*}{ Extension } & $0(-2-0)$ & $0(-2-0)$ & 0 & 0.067 \\
\hline & $4 / 23$ & $4 / 13$ & $0 / 10$ & \\
\hline \multirow[t]{2}{*}{ Hyperintensity } & $-4(-8-0)$ & $-4(-8--4)$ & $-2(-4-0)$ & 0.005 \\
\hline & $18 / 23$ & $13 / 13$ & $5 / 10$ & \\
\hline \multirow[t]{2}{*}{ Collections } & $0(-1-0)$ & $0(-1-0)$ & $0(-1-0)$ & 0.899 \\
\hline & $2 / 23$ & $1 / 13$ & $1 / 10$ & \\
\hline \multirow[t]{2}{*}{ Recital wall } & $0(-2-0)$ & $0(-2-0)$ & $0(-2-0)$ & 0.707 \\
\hline & $8 / 23$ & $5 / 13$ & $3 / 10$ & \\
\hline
\end{tabular}

Values presented in the table represent median with range and number of patients with changes. 
The overall PDAI in all the patients decreased significantly from 11 before treatment to five after treatment $(p<0.001)$. Also, overall MRIs decreased significantly from 10 before therapy to seven after treatment ( $p<$ $0.001)$. There was no significant difference between the groups of responders and non-responders regarding overall PDAI and MRIs before treatment ( $p=0.261$ and $p=0.551$, respectively). After therapy significant changes in overall PDAI and MRIs between the groups were observed. Overall PDAI in responders decreased to 0 while in non-responders it decreased only to seven ( $p=0.001$ ) (Table III). In turn, MRIs in group I dropped to 4 while in group II it dropped to $9.5(p=0.004)$ (Table III).

Linear regression analysis (Table $\mathrm{V}$ ) shows that the relation to sphincter and fistula complexity significantly increased the PDAl after treatment ( $\beta=0.568$ and 0.546 , respectively), what means, that for the branched and transsphincteric fistulas the effect of therapy was less significant. Two factors of the model: gender and MRI before treatment, have a lower $(\beta=-0.394$, and -0.391 , respectively) and non-significant effect on the PDAI result. The model including these four variables turned out to be statistically significant $(p=0.007)$ with $R^{2}$ of 0.418 with a large effect size $\left(f^{2}=0.72\right)$. The limitation of this model is the reduced tolerance of its two components: the fistula complexity and MRI before treatment, which is the consequence of moderate correlation of these two variables (Spearman correlation coefficient $R=0.5$ ). However, the removal of the variable MRI before treatment from the model resulted in decreasing model parameters $\left(R^{2}=0.367\right.$, effect size $\left.f^{2}=0.58\right)$ and loss of statistical significance of fistula complexity. Another three considered variables: age, number of tracts, and extension, turned out not to be statistically significant and they were not included in the model.

\section{Discussion}

The implementation of biological therapy represents a major advance in the treatment of CF. Conservative surgery, in the form of incision and drainage, is combined today with biological therapy to improve the rate of response and to prolong the time of remission. However, results of that treatment are still unsatisfactory [5]. Nonetheless, several clinical classifications of CF activity and healing have been adopted, such as fistula drainage assessment, and the PDAl among others; a comprehensive method assessing the fistula healing process is not yet available $[5,6]$. All of the aforementioned scores are dynamic measures that allow monitoring of treatment, and they show significant response to the combined therapy. Certain response to treatment, occurring in over $50 \%$ of the surveyed patients,
Table V. Predictors of the PDAl after treatment - linear regression analysis

\begin{tabular}{lccc} 
Model & $\begin{array}{c}\text { Standardized } \\
\text { coefficients }(\beta)\end{array}$ & $\boldsymbol{t}$ & $\boldsymbol{P}$-value \\
\hline Constant & & 2.065 & 0.054 \\
\hline $\begin{array}{l}\text { Relation to } \\
\text { sphincters }\end{array}$ & 0.568 & 3.013 & 0.007 \\
\hline $\begin{array}{l}\text { Fistulas } \\
\text { complexity }\end{array}$ & 0.546 & 2.352 & 0.030 \\
\hline Gender & -0.394 & -2.010 & 0.059 \\
\hline $\begin{array}{l}\text { MRI before } \\
\text { treatment }\end{array}$ & -0.391 & -1.640 & 0.118
\end{tabular}

may be proven by the results of this investigation. However, the healing process within a fistulous tract is not adequately represented in those scores. Perhaps, inaccurate assessment of that process is a cause of less effective treatment, among others. The need for withdrawal of biological medications is determined most commonly on a clinical basis, if alleviation of pain occurs, discharge from the fistulous orifice decreases and reduction of perianal skin induration occurs [9]. Authors from St Mark's Hospital found that the process of an anal fistula closure was slower to occur than the clinically recognised healing, and the rate of healing varied among patients. That process, according to the authors, spanned on average 12 to 24 months [10]. It seems that after initial treatment with biological therapies, healing of the cutaneous, external opening occurs earlier than healing of the fistulous tract. In other words, cessation of discharge from the external orifice is a result of healing of a fistula from the external opening instead of the internal one, and the external cutaneous openings close earlier compared to healing of the mesenchymal tract. Although the results of the present survey showed significant reduction of inflammatory process within the fistulous canal after induction therapy, with complete resolution of inflammatory infiltration in three fourths of the patients with clinical response, complete closure of the tracts was visualised on MRI in half of those patients with clinical healing. Complete closure of fistulas after combined treatment with biological therapies, confirmed on MRI, also varied significantly according to other studies. van Assche et al. proved that fistulous tracts remained visible in $70 \%$ of the patients with clinical response [8]. In the study by $\mathrm{Ng}$ et al., clinical healing of fistulas occurred in $46 \%$ of patients treated with biological medications at 18 months, whereas MRI showed fibrosis of fistulas in $28 \%$ of patients [11]. Karmiris et al. reported persistence of fistula tracts on MRI, after long-term follow-up in almost 

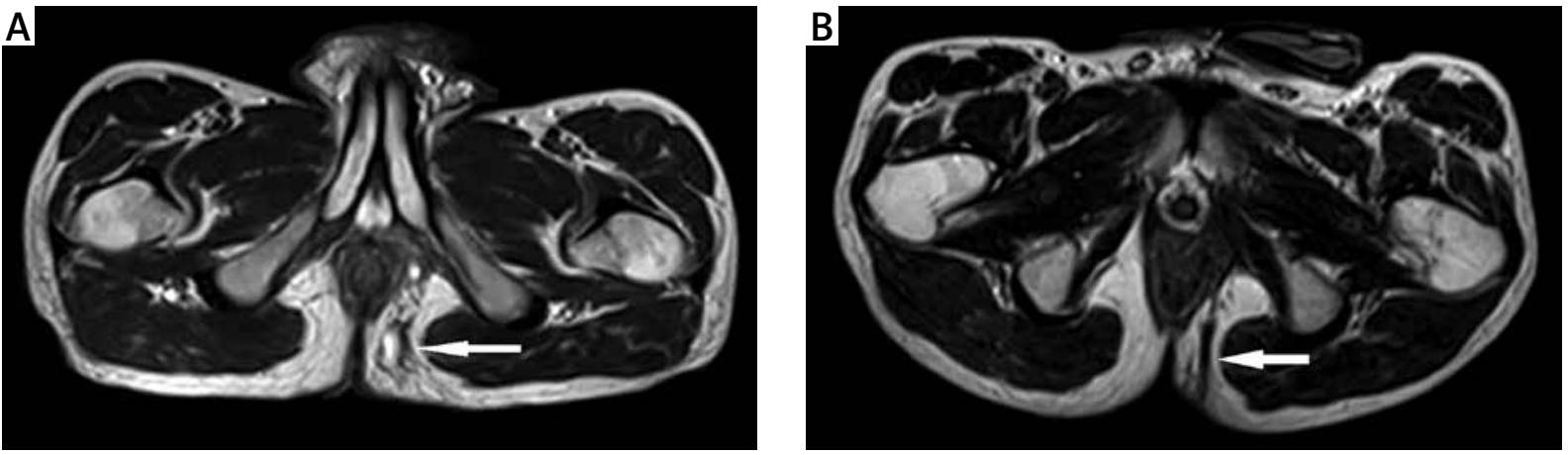

Figure 2. Magnetic resonance T2-weighted image. Transsphincteric infralevatoric anal fistula before (A) or after (B) treatment. Lumen of the fistula is hyperintense due to the presence (A) or absence (B) of fluid

$80 \%$ of the surveyed patients, whereas improvement in the inflammation was seen in half of the patients [12]. Therefore, there was a need for more accurate methods of fistula closure assessment, because the discrepancy in healing might be associated with an increased risk of fistula recurrence. Today MRI of the pelvis appears to be the method of choice for accurate characterisation of anal fistulas in CD. van Assche et al. developed an MRI score of disease activity for patients with anal fistulas in $C D$ to evaluate response to treatment. That score consists of parameters reflecting topographic anatomy and inflammation within a fistula [8]. Assessment of local inflammatory activity is based on hyperintense T2-weighted appearance of a fistula tract or cavities and thickening of the rectal wall. The signal is hyperintense in T2-weighted images due to increased fluid content, which is assumed to correspond properly with the inflammatory process. It is thought that a fall in signal intensity indicates less fluid content, decreasing inflammatory activity and as a result also the healing process. Hyperintensity within a fistulous tract is the most accurate indicator of inflammation. It seems that biological treatment should be continued in some patients until hypointense scar tissue within a fistulous tract appears (Figures 2 A, B). In other words, fibrosis of a fistula tract remains the most accurate radiological sign of healing to justify withdrawal of the biological therapy [12]. Endorectal ultrasound (ERUS) is a useful alternative to MRI in diagnosing CF. However, the accuracy of this method can be limited by its restricted view because it cannot accurately identify ischioanal fossa or supralevator abscesses. In addition, the use of endoluminal probes can be limited by the anal or rectal strictures, and the abovementioned hypointense scar tissue within the fistulous canal imaged on MRI turns out to be the most accurate radiological sign of fistula closure [7]. However, radiological closure of a fistula is an uncommon outcome, and any response to treatment in the form of alleviation of symptoms is already a de- sirable result in most patients [13]. However, there are some limitations of this study, such as the retrospective nature of this series, and the small number of patients; the results might be applied for further meta-analysis. What is more, prolonged biological therapy according to MRI requires further prospective studies.

\section{Conclusions}

The healing process of Crohn's anal fistulas should be monitored by MRI due to the discrepancy between premature closure of external openings compared to fistulous tracts. Prolonged biological therapy until complete healing of Crohn's anal fistulas, confirmed on MRI, might improve the results of treatment.

\section{Conflict of interest}

The authors declare no conflict of interest.

\section{References}

1. Lichtenstein GR, Yan S, Bala M, et al. Infliximab maintenance treatment reduces hospitalizations, surgeries, and procedures in fistulizing Crohn's disease. Gastroenterology 2005; 128 : 862-9.

2. Sands BE, Blank MA, Diamond RH, et al. Maintenance infliximab does not result in increased abscess development in fistulizing Crohn's disease: results from the ACCENT II study. Aliment Pharmacol Ther 2006; 23: 1127-36.

3. Gionchetti P, Dignass A, Danese S, et al. $3^{\text {rd }}$ European Evidence-based Consensus on the Diagnosis and Management of Crohn's Disease 2016: Part 2: Surgical Management and Special Situations. J Crohns Colitis 2017; 11: 135-49.

4. Parks AG, Gordon PH, Hardcastle JD. A classification of fistula-in-ano. Br J Surg 1976; 63: 1-12.

5. Present DH, Rutgeerts P, Targan S, et al. Infliximab for the treatment of fistulas in patients with Crohn's disease. N Engl J Med 1999; 340: 1398-405.

6. Irvine EJ. Usual therapy improves perianal Crohn's disease as measured by a new disease activity index. McMaster IBD Study Group. J Clin Gastroenterol 1995; 20: 27-32. 
7. Chidi VN, Schwartz DA. Imaging of perianal fistulizing Crohn's disease. Expert Rev Gastroenterol Hepatol 2015; 9: 797-806.

8. Van Assche G, Vanbeckevoort D, Bielen D, et al. Magnetic resonance imaging of the effects of infliximab on perianal fistulizing Crohn's disease. Am J Gastroenterol 2003; 98: 332-9.

9. Eitan A, Koliada M, Bickel A. The use of the loose seton technique as a definitive treatment for recurrent and persistent high trans-sphincteric anal fistulas: a long-term outcome. J Gastrointest Surg 2009; 13: 1116-9.

10. Colombel JF, Schwartz DA, Sandborn WJ, et al. Adalimumab for the treatment of fistulas in patients with Crohn's disease. Gut 2009; 58: 940-8.

11. Ng SC, Plamondon S, Gupta A, et al. Prospective evaluation of anti-tumor necrosis factor therapy guided by magnetic resonance imaging for Crohn's perineal fistulas. Am J Gastroenterol 2009; 104: 2973-86.

12. Karmiris K, Bielen D, Vanbeckevoort D, et al. Long-term monitoring of infliximab therapy for perianal fistulizing Crohn's disease by using magnetic resonance imaging. Clin Gastroenterol Hepatol 2011; 9: 130-6.

13. Tougeron D, Savoye G, Savoye-Collet C, et al. Predicting factors of fistula healing and clinical remission after infliximab-based combined therapy for perianal fistulizing Crohn's disease. Dig Dis Sci 2009; 54: 1746-52.

Received: 9.09.2018

Accepted: 7.10 .2018 